\title{
Painful Os Peroneum Syndrome Presenting as Lateral Plantar Foot Pain
}

\author{
Seon Jeong Oh, M.D., Young Hoon Kim, M.D., Ph.D. ${ }^{2}$, Sun Ki Kim, M.D. ', Min-Wook Kim, M.D., Ph.D.
}

Departments of Rehabilitation Medicine and ${ }^{1}$ Radiology, Incheon St. Mary's Hospital, The Catholic University of Korea, Incheon 403-720, ${ }^{2}$ Department of Orthopedic Surgery, Seoul St. Mary's Hospital, The Catholic University of Korea, Seoul 137-701, Korea

Lateral plantar foot pain can be caused by various entities, and the painful os peroneum syndrome should be considered in the differential diagnosis. Recent developments in musculoskeletal ultrasonography are very useful for initial diagnosis. We discuss a 69-year-old female who experienced lateral plantar foot pain for over one month. Through physical examination, radiography, ultrasound and magnetic resonance imaging, she was diagnosed with the painful os peroneum syndrome with a chronic fatigue fracture of multipartite os peroneum and peroneus longus tenosynovitis, for which she underwent surgery. We herein report this rare condition and reviewed the relevant literature.

Key Words Painful os peroneum syndrome, Lateral plantar foot pain

\section{INTRODUCTION}

The os peroneum is a round or oval-shaped accessory ossicle within the substance of the peroneus longus tendon, located near the cuboid bone. It consists of a mixture of bony and fibrocartilage tissues. ${ }^{1,2}$ Peroneus longus is a strong foot evertor its tendon passes downwards around the lateral malleolus on the lateral surface of the calcaneum, and the groove of the cuboid, to enter the sole of the foot. ${ }^{2}$ The os peroneum can occur in this tendon at the calcaneocuboid articulation. The

Received May 24, 2011; Accepted August 16, 2011

Corresponding author: Min-Wook Kim

Department of Rehabilitation Medicine, Incheon St. Mary's Hospital, The Catholic University of Korea, 56, Dongsu-ro, Bupyung-gu, Incheon 403720 , Korea

Tel: +82-32-510-5858, Fax: +82-32-510-5040, E-mail: minukkim@nate. com

(c) This is an open-access article distributed under the terms of the Creative Commons Attribution Non-Commercial License (http:// creativecommons.org/licenses/by-nc/3.0) which permits unrestricted noncommercial use, distribution, and reproduction in any medium, provided the original work is properly cited.

Copyright () 2012 by Korean Academy of Rehabilitation Medicine presence of an os peroneum has been reported between $4.7 \%$ and $30 \%$ of normal feet, and some cases ( $40 \%$ ) were unilateral. $^{2-4}$

The painful os peroneum syndrome (POPS), a term coined by Sobel et al., ${ }^{5}$ results from a spectrum of conditions, including os peroneum fracture or a diastasis of multipartite os perineum. Either of the aforementioned causes may result in discontinuity of the peroneus longus tendon or peroneus longus tenosynovitis.

We report a rare case of chronic POPS in a 69 yearold female who experienced lateral foot pain for over one month we present the plain film, sonographic and magnetic resonance imaging (MRI) findings. To the authors' knowledge, there is no published report, in existing Korean literature, ${ }^{6,7}$ of chronic POPS without associated peroneus longus tendon rupture as a cause of lateral plantar foot pain, with the exception of two case reports of acute POPS with peroneus longus tendon rupture. This case is distinguishable in the aspect that chronic POPS is more easily overlooked and is rarely reported as an acute condition, and this is the first 
case report with initial ultrasonography as the key for diagnosis.

\section{CASE REPORT}

A 69-year-old female presented to the outpatient clinic with over one month of persistent right lateral plantar foot pain. There had been no history or memorable traumatic episode. Pain waxed and waned in spite of conservative treatment in a local clinic. The patient had been treated for diabetes mellitus for 10 years and hypertension for 2 years. On physical examination, there was marked tenderness over the cuboid. Pain was elicited on active and resisted plantar flexion of the first ray of the right foot.

Plain oblique view of the right foot radiograph exhibited multipartite os peroneumbeside the cuboid, which

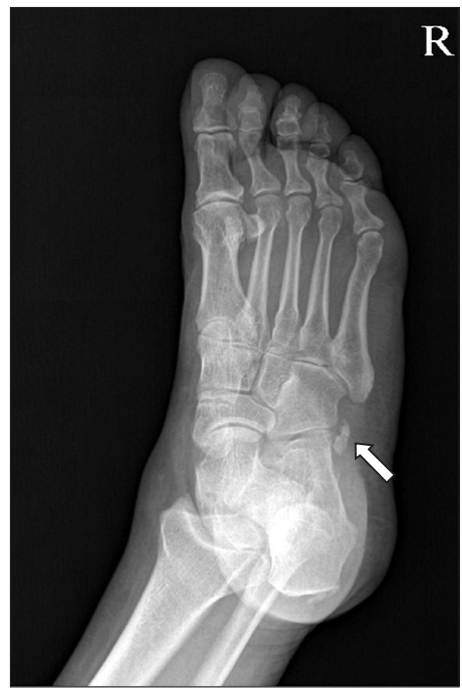

Fig. 1. Oblique view of the foot shows multipartite os peroneum at the level of the calcaneocuboid articulation (arrow).


Fig. 3. Sagittal (A) and coronal (B) fat-suppressed contrast-enhanced T1-weighted image (TR/TE 780/12) demonstrates os peroneum (arrow) near the cuboid bone, which is in the inflamed peroneus longus tendon (arrowheads).
Fig. 2. Longitudinal ultrasonography view shows tenosynovitis (arrow) of the peroneus longus tendon (empty arrowhead) aligned to os peroneum (arrowhead)(A), and transverse ultrasonography view shows cortical disruption of the os peroneum (arrowheads) (B). 

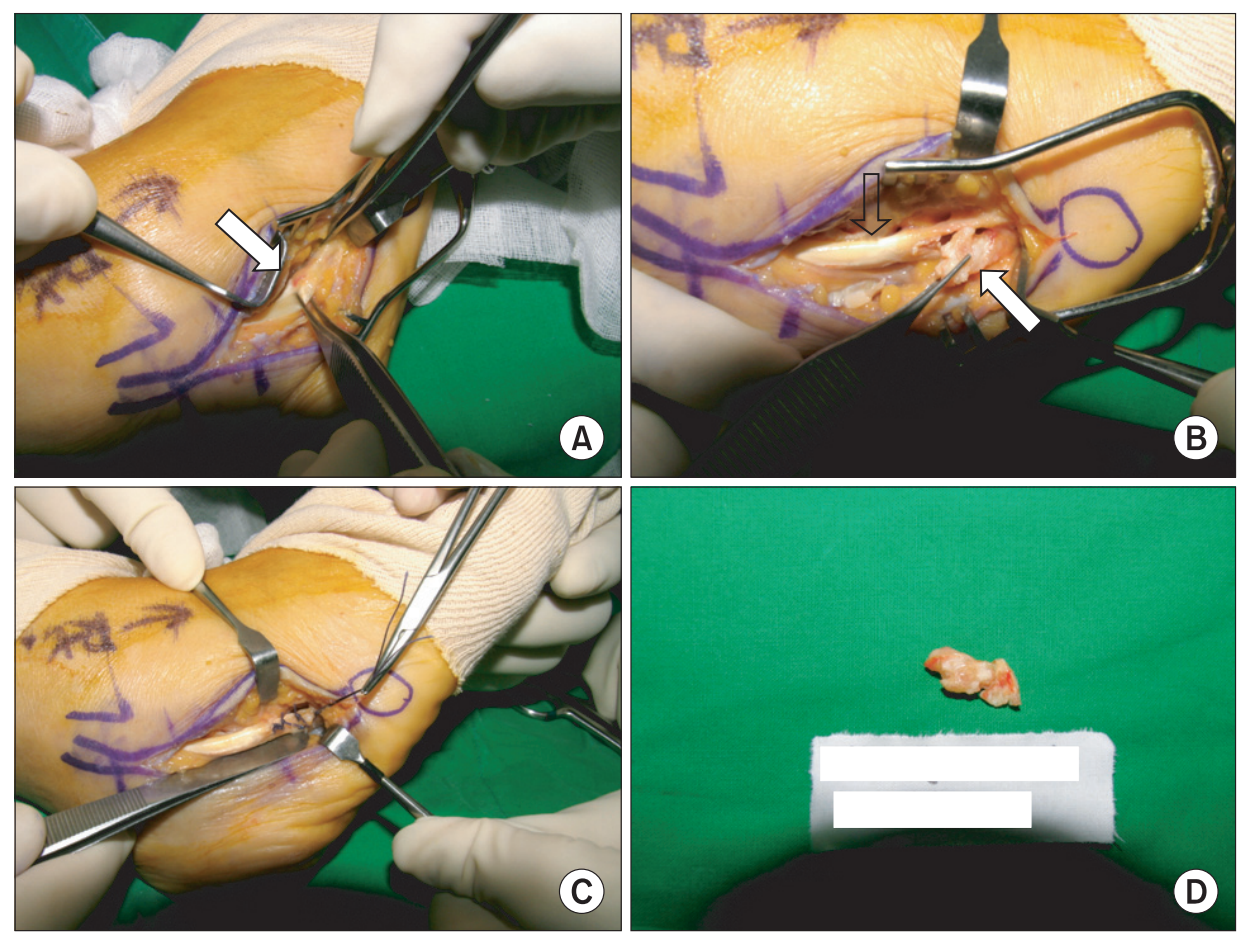

Fig. 4. Intraoperative photograph shows an os peroneum (arrow) in the peroneus longus tendon (A), peroneus longus tendon (empty arrow), and excision of multipartite os peroneum (arrow) (B), anastomosis of peroneus longus tendon $(\mathrm{C})$, and the excised multipartite os peroneum (D). grossly measured $5 \times 15 \mathrm{~mm}$ in size and was irregularly ovoid in shape (Fig. 1). Sonography showed multipartite os peroneum with disrupted hyperechoic surfaces and tenosynovitis of the peroneus longus tendon (Fig. 2). MRI revealed multipartite os peroneum in the inflamed peroneus longus tendon adjacent to the cuboid bone (Fig. 3). A diagnosis of painful os peroneum syndrome with fatigue fracture of multipartite os peroneum and peroneus longus tenosynovitis was made.

Intraoperatively, multipartite os peroneum was in the thinned and degenerated peroneus longus tendon. The peroneal sheath was edematous, and the peroneus longus tendon was not ruptured. Excision of the os peroneum and primary anastomosis with synovectomy were performed (Fig. 4). The patient was discharged with a splint she made a good recovery, and her lateral foot pain resolved. Postoperative oblique views of the right foot did not show ossified lesions.

\section{DISCUSSION}

There are multiple causes of lateral foot pain, including dislocation or subluxation of the peroneal tendon, injury of the anterior talofibular ligament, or the calcaneofibularligament, and fracture of thefifth metatarsal, anterior process of the calcaneus and cuboid.
POPS as the cause of lateral foot pain can be easily overlooked due to its rareness, lack of doctors' suspicion of it, absence of traumatic episode in chronic cases, presence of normal bipartite or multipartite ossicles, and our basic concept of sesamoid bone that protectsthe tendon from injury being located in a particular area of the foot.

Awareness of various clinical and radiological findings can prevent prolongation of undiagnosed lateral plantar foot pain. POPS as a cause of lateral plantar foot pain is a rare condition but should be suspected in clinics. POPS has two major presentations: acute and chronic. ${ }^{5}$ Acute presentation occurs as a result ofsudden trauma, commonly ankle supination and/or inversion injury, which results in os peroneum fracture or diastasis of multipartite os peroneum with subsequent disruption of the peroneus longus tendon, or frank rupture of the peroneus longus tendon. Chronic presentation follows poorly-defined repetitive or recurrent injuries to the foot. It is associated with the healing of a fracture with subsequent remodeling calcification or chronic diastasis of a multipartite os peroneum and stenosing peroneus longus tenosynovitis. Chronic presentation of POPS is highly risky if left undiagnosed, due to reasons listed above, and with the knowledge that our patient's symptom mimicked those of ankle sprain. 
Physical examination reveals swelling and tenderness over the cuboid bone area. Pain is exacerbated by resisted plantar flexion of the first ray and during the heel rise phase of gait. Eversion strength can be reduced. ${ }^{5}$

In the case presented, the patient had experienced lateral plantar foot pain for over one month, without a history of trauma. Plain radiography showed an accessory ossicle adjacent to the cuboid. Fatigue fracture of multipartite os peroneum is not easily distinguished from calcific tendonitis. In the literature, there are a few reports of calcific tendonitis of the peroneus longus tendon. ${ }^{8}$ However, these reports might actually represent chronic presentation of POPS. Chronic presentation of fractured os perineum, with subsequent healing callus, could be misdiagnosed as calcific tendonitis.

Histologically, fibrocartilages are present in tendons at the site where they wrap around the bony pulley. Mechanical stress leads to ossification at the center of the fibrocartilaginous portion of a tendon. Calcification is a process which occurs during ossification. Some os peroneum appeared as well-formed cancellous bony masses while others were diffuse and stippled with only a few trabeculae. As such, the os peroneum ranges in size from a small spicule to a bony mass. ${ }^{1}$ These small spicules are not composed of calcific tendonitis. Also, Sobel et al. ${ }^{5}$ insisted that there is no calcific tendonitis of the peroneus longus.

In the case presented, ultrasonography demonstrated bone fragment separation of $2 \mathrm{~mm}$ or less and pain under transducer pressure, suggesting fatigue fracture of multipartite os peroneum. Bony separation of $2 \mathrm{~mm}$ or less can be seen with multipartite os peroneum rather than os peroneum true fracture. ${ }^{9}$ Microfracture due to chronic repetitive weight loading could be the reason for the fatigue fracture of multipartite os peroneum.

We concluded that our patient should be classified as suffering from a chronic presentation of POPS, with chronic fatigue fracture of multipartite os peroneum associated with peroneal tenosynovitis.

Treatment includes casting, excision of the ossicle or tendon segment, direct tendon repair, direct boneto-bone repair, and attachment using a graft. ${ }^{5,6}$ In the case presented, because of severe tenosynovitis, fatigue fracture, and repetitive aggravation of pain, regardless of conservative treatment, excision of os peroneum and primary anastomosis with synovectomy were performed. In conclusion, we report a rare case of painful os peroneum syndrome with chronic fatigue fracture of multipartite os peroneum and peroneal tenosynovitis that presented with lateral plantar foot pain, along with a review of related literature.

\section{REFERENCES}

1. Benjamin M, Qin S, Ralphs JR. Fibrocartilage associated with human tendons and their pulleys. J Anat 1995; 187: 625-633

2. Le Minor JM. Comparative anatomy and significance of the sesamoid bone of the peroneus longus muscle (os peroneum). J Anat 1987 151: 85-99

3. Coskun N, Yuksel M, Cevener M, Arican RY, Ozdemir $\mathrm{H}$, Bircan O, Sindel T, Ilgi S, Sindel M. Incidnece of accessory ossicles and sesamoid bones in the feet: a radiographic study of the Turkish subjects. Surg Radiol Anat 2009; 31: 19-24

4. Muehleman C, Williams J, Bareither ML. A radiologic and histologic study of the os peroneum: prevalence, morphology, and relationship to degenerative joint disease of the foot and ankle in a cadaveric sample. Clin Anat 2009; 22: 747-754

5. Sobel M, Pavlov H, Geppert MJ, Thompson FM, DiCarlo EF, Davis WH. Painful os peroneum syndrome: a spectrum of conditions responsible for plantar lateral foot pain. Foot Ankle Int 1994; 15: 112124

6. Bae SY, Chung HJ, Oh JS. Fracture of os peroneum with rupture of the peroneus longus tendon-a case report. J Korean Foot Ankle Soc 2009; 13: 207-210

7. Kim YH, Kim KW, Min HJ, Yoon ES, Kim HO, Suh JS. Fracture of the os peroneumwith rupture of the peroneus longus tendon-a case report. J Korean Soc Fracture 2001; 14; 685-688

8. Cox D, Paterson FWN. Acute calcific tendinitis of peroneus longus. J Bone Joint Surg 1991; 73: 342

9. Brigido MK, Fessell DP, Jacobson JA, Widman DS, Craig JG, Jamadar DA, van Holsbeeck MT. Radiography and US of os peroneum fractures and associated peroneal tendon injuries: initial experience. Radiology 2005; 237: 235-241 